\title{
Evaluation of Anti-Inflammatory Activity of Citrus latifolia Tanaka Essential Oil and Limonene in Experimental Mouse Models
}

\author{
Raquel Kummer, ${ }^{1}$ Fernanda Carolina Fachini-Queiroz, ${ }^{1}$ Camila Fernanda Estevão-Silva, \\ Renata Grespan, ${ }^{1}$ Expedito Leite Silva, ${ }^{2}$ Ciomar Aparecida Bersani-Amado, ${ }^{1}$ \\ and Roberto Kenji Nakamura Cuman ${ }^{1}$ \\ ${ }^{1}$ Department of Pharmacology and Therapeutics, State University of Maringá, 870020-900 Maringá, PR, Brazil \\ ${ }^{2}$ Department of Chemistry, State University of Maringá, 870020-900 Maringá, PR, Brazil
}

Correspondence should be addressed to Raquel Kummer; raquelkummer@hotmail.com

Received 4 February 2013; Revised 18 April 2013; Accepted 23 April 2013

Academic Editor: Jang-Hern Lee

Copyright (C) 2013 Raquel Kummer et al. This is an open access article distributed under the Creative Commons Attribution License, which permits unrestricted use, distribution, and reproduction in any medium, provided the original work is properly cited.

\begin{abstract}
The genus Citrus (Rutaceae) includes several species of plants that produce some of the most cultivated fruits in the world, providing an appreciable content of essential oil. In folk medicine, they are used as a cholagogue, antipyretic, anti-inflammatory, sedative, and antitoxic effects. Lemon essential oil has been used since ancient times for its antiseptic, carminative, diuretic, and eupeptic effects. In this study, we investigated the anti-inflammatory activity of Citrus latifolia Tanaka essential oil (CLEO) and its main constituent LIM. In the cell viability assay, CLEO and $\operatorname{LIM}(3,10,30$, and $90 \mu \mathrm{g} / \mathrm{mL})$ had low cytotoxicity. In zymosan-induced peritonitis, LIM $(500 \mathrm{mg} / \mathrm{kg})$ decreased the infiltration of peritoneal exudate leukocytes and decreased the number of polymorphonuclear leukocytes. In vitro chemotaxis revealed that CLEO and $\operatorname{LIM}(1,3$, and $10 \mu \mathrm{g} / \mathrm{mL})$ promoted a significant reduction of neutrophil migration toward fMLP and $\mathrm{LTB}_{4}$. LIM $(500 \mathrm{mg} / \mathrm{kg})$ also reduced TNF- $\alpha$ levels but did not alter IL-10 levels in the peritoneal exudate. In conclusion, this study showed that LIM isolated from CLEO had potential anti-inflammatory effects, likely by inhibiting proinflammatory mediators present in inflammatory exudate and leukocyte chemotaxis.
\end{abstract}

\section{Introduction}

The genus Citrus (Rutaceae) includes several species of plants that produce some of the most cultivated fruits in the world, including oranges and lemons, which have an appreciable content of essential oil. In folk medicine, they are used as a cholagogue and for their digestive, tonic, antipyretic, antiinflammatory, sedative, and antitoxic effects [1-4]. Essential oils of plants from the genus Citrus have monoterpenes and sesquiterpenes as their constituents $[5,6]$. The literature indicates the presence of 50 or more different compounds obtained from citrus peel, whereas limonene (LIM) is the main compound $[3,7]$. Citrus latifolia Tanaka is popularly known as Tahiti lime and grows well in tropical regions [8].
Lemon essential oil is a complex mixture of LIM, $\gamma$ terpinene, citral, linalool, and $\beta$-caryophyllene, among others [9]. Since ancient times, it has been used for its antiseptic, carminative, diuretic, and eupeptic effects [2]. Some of its compounds, including $\beta$-caryophyllene, LIM, and linalool, have anti-inflammatory effects [10-12]; $\alpha$-pinene and $\beta$ pinene inhibit the synthesis of nitric oxide (NO), suggesting an antioxidant effect [3], and recent reports showed that $\beta$ pinene exerts an antispasmodic effect on the rat ileum and provokes antinociceptive actions [13].

LIM is one of the most common terpenes in nature and has been used as a flavoring agent in common food items, such as fruit juices, soft drinks, and ice cream, and in the cosmetics and pesticide industries [11, 14]. LIM has been 
shown to exert antiulcerogenic, gastroprotective, chemopreventive, antiproliferative, insecticide, antimicrobial, and immunomodulatory effects [15-18]. This compound has also been shown to have anti-inflammatory effects by reducing eosinophil chemotaxis and MCP-1 production [11]. It effectively inhibited lipopolysaccharide- (LPS-) induced NO and prostaglandin $\mathrm{E}_{2}\left(\mathrm{PGE}_{2}\right)$ production in macrophages [19] and decreased interleukin-1 $\alpha$ (IL- $1 \alpha)$ levels in normal human undifferentiated NCTC 2544 keratinocytes [20].

The biological activity of extracts of herbs has been widely studied, but few studies have evaluated the effects of essential oils obtained from plants of the genus Citrus and its constituents on anti-inflammatory activity. The present study investigated the anti-inflammatory activity of Citrus latifolia Tanaka essential oil (CLEO) and its main constituent, LIM.

\section{Materials and Methods}

2.1. Plant Material and Extraction of Essential Oil. The fruits of Citrus latifolia Tanaka were commercially purchased in Maringá, PR, Brazil. The essential oils were extracted from the flavedos of fruits of Citrus latifolia Tanaka (690 g) by conventional steam distillation using a Clevenger-type apparatus for $2 \mathrm{~h}$. The obtained essential oil was dried over sodium sulfate and stored at $4^{\circ} \mathrm{C}$ in dark vials until tested. The yield of CLEO was $2.76 \% \mathrm{v} / \mathrm{w}$. The constituent limonene was isolated from CLEO as fractions of hydrodistillated oil.

\subsection{Analysis of the Essential Oil and Compound Identification}

2.2.1. Gas Chromatography-Mass Spectrometry. Gas chromatography was performed with a Thermo Electron Corporation Focus GC model under the following conditions: DB5 capillary column $(30 \mathrm{~m} \times 0.32 \mathrm{~mm}, 0.50 \mathrm{~mm})$, column temperature $\left(60^{\circ} \mathrm{C}\right.$ for $1 \mathrm{~min}$ to $180^{\circ} \mathrm{C}$ at $\left.3^{\circ} \mathrm{C} / \mathrm{min}\right)$, injector temperature $\left(220^{\circ} \mathrm{C}\right)$, detector temperature $\left(220^{\circ} \mathrm{C}\right)$, split ratio $(1: 10)$, carrier gas $(\mathrm{He})$, and flow rate $(1.0 \mathrm{~mL} / \mathrm{min})$. The volume injected $(1 \mu \mathrm{L})$ was diluted in chloroform $(1: 10)$. The GC-MS analysis was performed in a Quadrupole mass spectrometer (DSQ II model, Thermo Electron Corporation) that operated at $70 \mathrm{~V}$. The identification of the individual compounds was based on comparisons of their GC retention indices on an apolar column and comparisons with mass spectra of authentic standards purchased from SigmaAldrich [21].

2.2.2. Nuclear Magnetic Resonance. Nuclear magnetic resonance (NMR) was used to prove the chemical structure of the essential oil constituents identified by GC-MS. ${ }^{13} \mathrm{C}$ NMR $(75.45 \mathrm{MHz})$ spectra were recorded in a deuterated chloroform $\left(\mathrm{CDCl}_{3}\right)$ solution using a Mercury-300BB spectrometer, with $\delta(\mathrm{ppm})$ and spectra referenced to $\mathrm{CDCl}_{3}(\delta 77.00$ for $\left.{ }^{13} \mathrm{C}\right)$ as an internal standard.

2.3. Animals. For the evaluation of anti-inflammatory effects, male BALB/c mice were used (20-25 g). The animals were obtained from the Central Animal House of the State University of Maringá. The animals were housed at $22 \pm$ $2{ }^{\circ} \mathrm{C}$ under a $12 \mathrm{~h} / 12 \mathrm{~h}$ light/dark cycle. The experimental protocols were approved by the Ethical Committee in Animal Experimentation of the State University of Maringá (CEAE/UEM066/2010).

2.4. Bioassays for Cytotoxic Activity. The MTT (3-[4,5-dimethylthiazol-2-yl]-2,5-diphenyl-2H-tetrazolium bromide) assay is based on the mitochondrial enzyme reduction of tetrazolium dye that detects and determines cell viability [22]. The neutrophils were obtained from the peritoneal cavity of $\mathrm{BALB} / \mathrm{c}$ mice $4 \mathrm{~h}$ after zymosan injection ( $1 \mathrm{mg} /$ cavity, i.p.). Briefly, the cells $\left(5 \times 10^{5}\right.$ cells/well) were exposed to CLEO (3, $10,30$, and $90 \mu \mathrm{g} / \mathrm{mL})$ or $\operatorname{LIM}(3,10,30$, and $90 \mu \mathrm{g} / \mathrm{mL})$ for $90 \mathrm{~min}$ at $37^{\circ} \mathrm{C}$ in $5 \% \mathrm{CO}_{2}$. CLEO and LIM emulsions were prepared with RPMI medium and emulsified by sonication. A volume of $10 \mu \mathrm{L}$ MTT ( $5 \mathrm{mg} / \mathrm{mL}$; Sigma) was added to each well. After $2 \mathrm{~h}, 150 \mu \mathrm{L}$ of the supernatant was removed, and $100 \mu \mathrm{L}$ of dimethyl sulfoxide was added to each well. The cells were incubated at $25^{\circ} \mathrm{C}$ for an additional $10 \mathrm{~min}$, and absorbance was measured using a Biochrom Asys Expert plus microplate reader (Asys) at a wavelength of $540 \mathrm{~nm}$. The values of the blank wells were subtracted from each well of treated and control cells. The percentage of viability was determined by the following formula:

$$
\% \text { Viable cells : } \frac{\text { Absorbance of the treated cells }- \text { Absorbance of the blank }}{\text { Absorbance of the control - Absorbance of the blank }} \times 100
$$

\subsection{Anti-Inflammatory Activity}

2.5.1. In Vitro Chemotaxis Assay. To evaluate the effects of CLEO and LIM on chemotaxis, neutrophils were obtained from the peritoneal cavity of BALB/c mice $4 \mathrm{~h}$ after the zymosan injection ( $1 \mathrm{mg} /$ cavity, i.p). The cell number was adjusted to $1 \times 10^{6}$ cells/mL in RPMI medium that contained $0.1 \%$ bovine serum albumin (BSA). The chemotaxis assay was performed using a 48-well microchemotaxis plate
(Neuro Probe), in which the chambers were separated by a polyvinylpyrrolidone-free polycarbonate membrane $(5 \mu \mathrm{m}$ pore size). The chemoattractants $N$-formyl methionyl leucyl phenylalanine (fMLP; $\left.10^{-6} \mathrm{M}\right)$ and $\operatorname{LTB}_{4}\left(10^{-8} \mathrm{M}\right)$ and a negative control (RPMI 1640) were placed in the lower chamber. A neutrophil suspension $\left(1 \times 10^{6}\right.$ cells $\left./ \mathrm{mL}\right)$ pretreated with CLEO $(1,3$, or $10 \mu \mathrm{g} / \mathrm{mL})$ and $\operatorname{LIM}(1,3$, or $10 \mu \mathrm{g} / \mathrm{mL})$ for 30 min was then placed in the upper chamber. CLEO and LIM emulsions were prepared with RPMI and emulsified 
by sonication. The cells were allowed to migrate into the membrane for $1 \mathrm{~h}$ at $37^{\circ} \mathrm{C}$ in $5 \% \mathrm{CO}_{2}$. Following incubation, the membrane was washed and stained using Instant Prov (Newprove). The membrane area of each well was scored using light microscopy to count the intact cells present in five random fields. The results are expressed as the mean number of neutrophils per field and representative of three separate experiments.

2.5.2. Zymosan-Induced Peritonitis in Mice. In vivo neutrophil migration was performed in $\mathrm{BALB} / \mathrm{c}$ mice. Mice were pretreated with $\operatorname{LIM}(125,250$, or $500 \mathrm{mg} / \mathrm{kg}$, p.o.) or $0.2 \%$ of an aqueous Tween 80 solution $(0.1 \mathrm{~mL}$, p.o.) as the control. Thirty minutes later, all of the animals received an intraperitoneal zymosan injection ( $1 \mathrm{mg} /$ cavity) or an equivalent volume of vehicle (saline). Six hours after the animals were sacrificed, the cells present in the peritoneal cavity were harvested by introducing $2.0 \mathrm{~mL}$ of phosphate-buffered saline (PBS) that contained ethylenediaminetetraacetic acid (EDTA). Counts were then performed in total and differential cells. The results are expressed as the number of neutrophils.

2.5.3. Measurements of Cytokine Levels by Enzyme-Linked Immunosorbent Assay. The levels of TNF- $\alpha$ and IL-10 were determined in peritoneal exudate in $\mathrm{BALB} / \mathrm{c}$ mice. The group of mice was pretreated with LIM (500 mg/kg, p.o.) or $0.2 \%$ of an aqueous Tween 80 solution $(0.1 \mathrm{~mL}$, p.o.) as the control. Thirty minutes later, all of the animals received an intraperitoneal zymosan injection ( $1 \mathrm{mg} /$ cavity) or an equivalent volume of vehicle (saline). Six hours after the animals were sacrificed, the exudate present in the peritoneal cavity was harvested by introducing $1.0 \mathrm{~mL}$ of PBS that contained EDTA. The samples were centrifuged at 1000 rotations per minute for $10 \mathrm{~min}$ at $4^{\circ} \mathrm{C}$. The supernatant was separated for dosing and rapidly frozen and stored at $-70^{\circ} \mathrm{C}$ for later analysis. We used commercial kits for the enzymelinked immunosorbent assay according to the manufacturer's recommendations (R\&D Systems, Cayman Chemical).

2.6. Statistical Analysis. The data are expressed as the mean \pm SEM for each group. The data were statistically analyzed using one-way analysis of variance followed by Tukey's test and Student's $t$-test. Differences were considered significant at $P<0.05$.

\section{Results and Discussion}

The chemical composition of CLEO was investigated by gas chromatography-mass spectrometry (GC-MS) and nuclear magnetic resonance (NMR). The results of the GC-MS analysis (Figure 1) showed a predominance of LIM (62\%), $\gamma$ terpinene $(14.2 \%), \beta$-pinene $(12.2 \%), \alpha$-pinene $(2.8 \%)$, and p-cymene $(1.8 \%)$, similar to previous studies $[3,6,7]$. A complete list of the components and their relative abundances is presented in Table 1. To confirm the structure of the main compounds, CLEO was studied by ${ }^{13} \mathrm{C}$ NMR (Figure 2). The chemical shift of each carbon in the experimental spectrum was compared with shifts of the spectra of pure compounds.

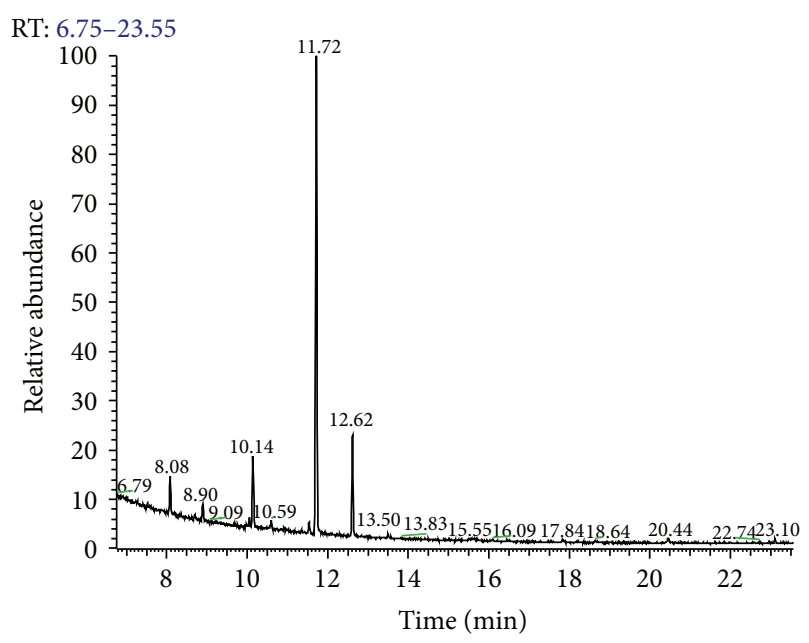

FIgure 1: GC chromatogram of Citrus latifolia Tanaka essential oil. Percentual data were obtained by gas chromatography-mass spectrometry (GC-MS). Peak identification is reported in Table 1.

In the cell viability assay, the treatments were tested at different concentrations. CLEO at concentrations of 3,10, 30 , and $90 \mu \mathrm{g} / \mathrm{mL}$ showed cell viability of $85 \%, 79 \%, 75 \%$, and $77 \%$, respectively. LIM at concentrations of 3, 10, 30, and $90 \mu \mathrm{g} / \mathrm{mL}$ showed cell viability of $88 \%, 78 \%, 77 \%$, and $79 \%$, respectively. Our data indicated that the CLEO and LIM treatments did not present in vitro cytotoxicity at any of the concentrations tested, with viability $>75 \%$ at a concentration of $10 \mu \mathrm{g} / \mathrm{mL}$, similar to a cytotoxicity study of plants from the genus Citrus $[3,14]$.

Neutrophils are first responders in an organism's rapid assault on infectious pathogens [23]. A recent study suggested that signals that arise from formyl-Met-Leu-Phe (fMLP) may predominate in directing the responses of neutrophils that have migrated to the final site of an infection [24]. The formyl peptide fMLP is a bacterial product that is recognized by neutrophils upon binding to its heterotrimeric $G$ proteincoupled receptor, initiating signaling cascades that activate multiple pathways. These pathways include the mitogenactivated protein kinase (MAPK) and phosphatidylinositol 3-kinase (PI-3K) cascades, which are important for the development of the functional responses of neutrophils in inflammation [23, 25]. To evaluate the direct effects of CLEO and LIM on in vitro neutrophil chemotaxis, different concentrations were applied. The chemoattractants fMLP $\left(10^{-6} \mathrm{M}\right)$ and leukotriene $\mathrm{B}_{4}\left(\mathrm{LTB}_{4} ; 10^{-8} \mathrm{M}\right)$ were used. CLEO at doses of 1,3 , and $10 \mu \mathrm{g} / \mathrm{mL}$ significantly reduced $(P<$ $0.05)$ neutrophil migration in response to fMLP stimulation (31.32\%, 40.85\%, and $45.45 \%$, resp.). LIM treatment at the same doses significantly reduced $(P<0.05)$ neutrophil migration in response to fMLP stimulation $(38.68 \%, 82.14 \%$, and $87.63 \%$, resp.; Figures 3(a) and 3(b)).

$\mathrm{LTB}_{4}$ is a potent chemoattractant derived from arachidonic acid. It modulates diverse functions in living systems (e.g., it induces chemotaxis) [26, 27]. CLEO at doses of 1, 3, and $10 \mu \mathrm{g} / \mathrm{mL}$ significantly reduced $(P<0.05)$ neutrophil migration in response to $\mathrm{LTB}_{4}$ stimulation $(32.86 \%, 34.80 \%$, 
TABle 1: Percentual chemical composition of the Citrus latifolia Tanaka essential oil.

\begin{tabular}{lccc}
\hline Retention time & Compound & Percentual (\%) & Identification $^{\text {a }}$ \\
\hline 8.08 & Solvent & - & MS $^{\mathrm{a}}$ \\
8.90 & $\alpha$-pinene & 2.8 & MS, NMR \\
10.14 & $\beta$-pinene & 12.2 & MS, NMR \\
10.59 & Solvent & - & MS \\
11.54 & $p$-cymene & 1.8 & MS, NMR \\
11.72 & Limonene & 62.0 & MS, NMR \\
12.62 & $\gamma$-terpinene & 14.2 & MS, NMR \\
13.50 & Linalool & 0.9 & MS, NMR \\
13.83 & Neral & 1.6 & MS, NMR \\
15.55 & Geranial & 0.6 & MS, NMR \\
17.80 & - & 0.6 & No identified \\
20.40 & $\alpha$-terpineol & 1.4 & MS, NMR \\
28.29 & - & 0.6 & No identified \\
24.8 & $\beta$-caryophyllene & 1.7 & MS \\
\hline
\end{tabular}

${ }^{*}$ Chloroform $\left(\mathrm{CHCl}_{3}\right)$.

${ }^{\text {a }}$ Mass spectrometry.

${ }^{\mathrm{b}}$ Nuclear magnetic resonance.

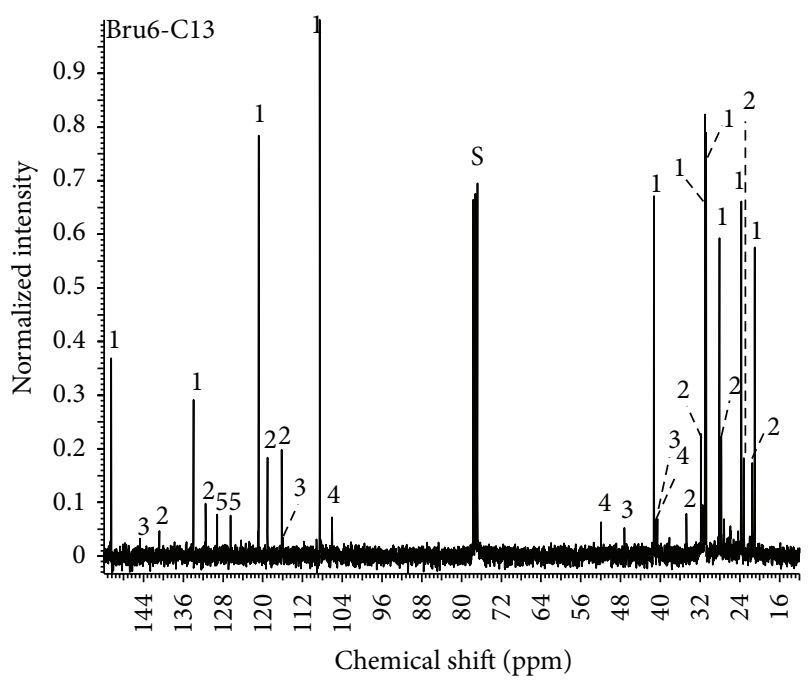

Figure 2: ${ }^{13} \mathrm{C}$ NMR spectra of the Citrus latifolia Tanaka essential oil in deuterated chloroform $\left(\mathrm{CDCl}_{3}\right)$. The numbers on the peaks are attributed to majority compounds: (1) Limonene, (2) $\gamma$-terpinene, (3) $\beta$-pinene, (4) $\alpha$-pinene, (5) $p$-cymene. $S=$ solvent chloroform $\left(\mathrm{CHCl}_{3}\right)$.

and $54.84 \%$, resp.). LIM treatment at the same doses also significantly reduced $(P<0.05)$ neutrophil migration in response to $\mathrm{LTB}_{4}$ stimulation $(29.48 \%, 36.82 \%$, and $34.52 \%$, resp.; Figures 3(c) and 3(d)). fMLP and $\mathrm{LTB}_{4}$ were used as chemotaxic agents in the in vitro tests, and CLEO and LIM inhibited neutrophil migration. Our results indicate that prostanoids and cytokines are involved in this process, in which CLEO and LIM did not affect neutrophil viability at the concentrations tested, suggesting that the direct effects of the treatments on the inhibition of neutrophil chemotaxis did not occur because of toxic effects that induced cell death.
Recent studies support these results. Lemon essential oil inhibited the activity of 5-lipoxygenase (5-LOX), and the inhibitory effect of LIM was observed in eotaxin-induced eosinophil chemotaxis $[11,28]$. Neutrophils have many cell surface receptors that are coupled to PI3K-dependent processes, including chemotaxis receptors [29]. In an underagarose assay, neutrophils predominantly migrated toward the fMLP chemoattractant via p38 MAPK, whereas $\mathrm{LTB}_{4}$ induced migration (i.e., an intermediary chemoattractant) was PI3K dependent $[24,30]$. Our results of the chemotaxis assay showed that both CLEO and LIM significantly inhibited chemotaxis induced by stimulation with fMLP and $\mathrm{LTB}_{4}$. However, preincubation of the neutrophils with LIM promoted a more intense inhibition of migration induced by fMLP compared with CLEO. fMLP-induced leukocyte migration involves prostanoid release [31], and the mechanism of action of these substances may be related to the inhibition of cyclooxygenases 1 and 2. Thus, we studied the effects of LIM on the in vivo inflammatory response.

Acute inflammation, typically characterized by redness, swelling, pain, and heat, is one of the most important defense mechanisms against invading pathogens [20]. Zymosan, the insoluble polysaccharide component of the cell walls of Saccharomyces cerevisiae, is commonly used for the induction of acute peritonitis in mice. In the zymosan-induced inflammatory process, several cytokines, such as tumor necrosis factor (TNF) and interleukin-6 (IL-6), are released. Activation of the complement cascade induces neutrophil accumulation and vascular abnormalities [32, 33]. In BALB/C mice, zymosan-induced peritonitis began with pronounced intraperitoneal plasma exudation associated with increased histamine levels. This was followed by an influx of neutrophils and mononuclear leukocytes, increased levels of plasma/peritoneal fluid chemoattractants (including MCP-1), and the sequential appearance of exudate proinflammatory cytokines (i.e., TNF- $\alpha$ followed by IL-1 $\beta$ and IL-6) [32]. Essential oil treatments, including Zingiber officinale Roscoe, Rosmarinus officinalis L., Cordia verbenacea, Pelargonium asperum, and Thymus vulgaris L. essential oils, have been shown to effectively reduce neutrophil chemotaxis [20, 3437].

To evaluate the effects of LIM pretreatment on the migration of inflammatory cells in vivo, peritonitis was induced by zymosan. After $6 \mathrm{~h}$ of peritonitis induction, an intense inflammatory response was observed, characterized by an increase in the number of peritoneal exudate leukocytes $\left(14.65 \pm 2.08 \times 10^{6}\right.$ cells/cavity) compared with the control group $\left(5.25 \pm 0.59 \times 10^{6}\right.$ cells/cavity). Many inflammatory mediators are involved in leukocyte migration, such as chemokines, leukotrienes, inflammatory cytokines, and prostaglandins $[38,39]$. The animals pretreated with LIM $(500 \mathrm{mg} / \mathrm{kg})$ presented a significant reduction of peritoneal exudate leukocyte infiltration compared with untreated animals (Figure 4(a)). The decrease in the number of leukocytes was mainly attributable to a reduction of the number of polymorphonuclear leukocytes (Figure 4(b)).

The inflammatory response includes the recruitment of leukocytes and release of inflammatory cytokine, such as 


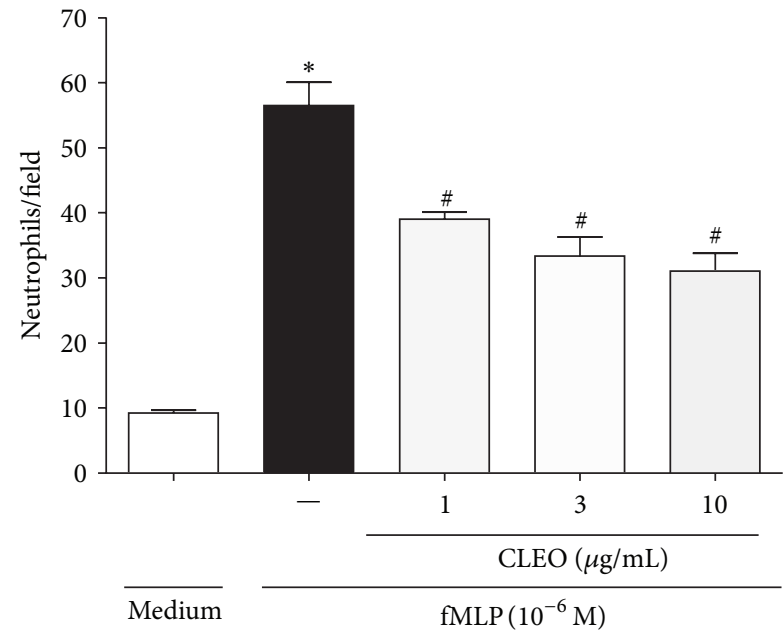

(a)

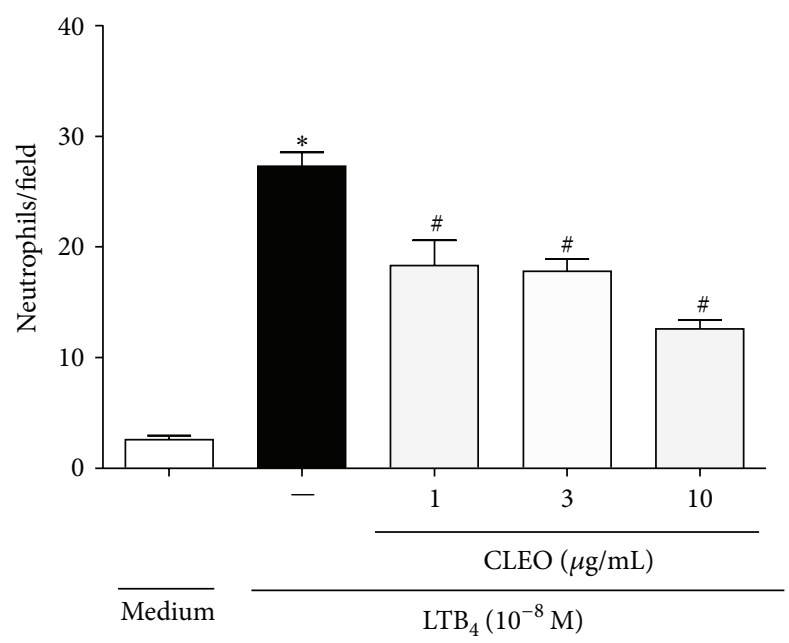

(c)

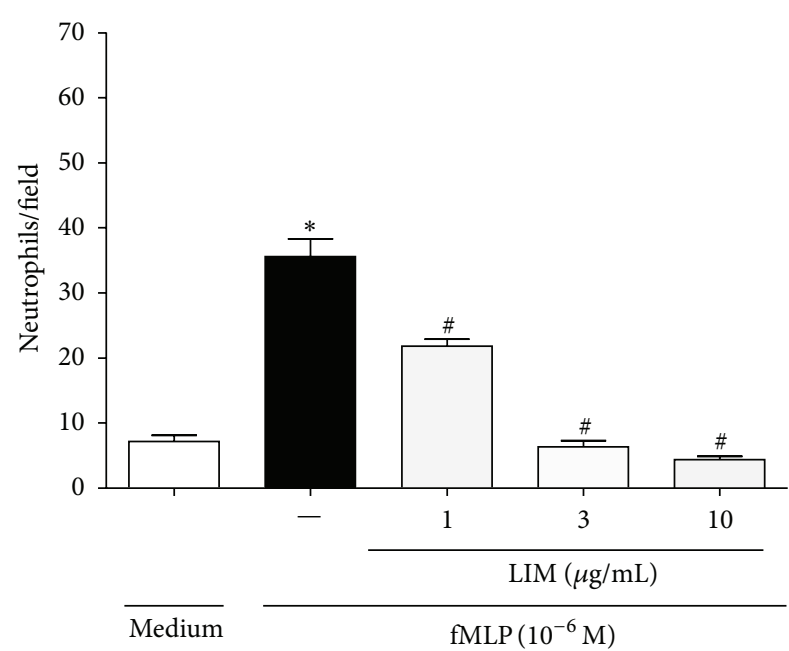

(b)

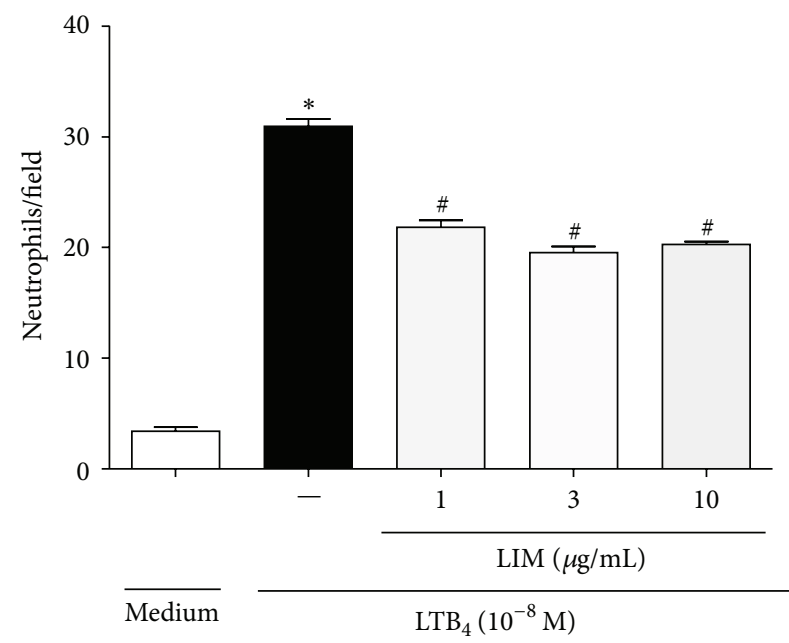

(d)

FIGURE 3: Effect of CLEO and LIM on neutrophils chemotaxis in vitro. Neutrophils were obtained from zymosan-induced peritonitis $\left(1 \mathrm{mg} /\right.$ cavity, ) and stimulated with fMLP $\left(10^{-6}\right)$ or $\operatorname{LTB}_{4}\left(10^{-8}\right)$ after 30 min of treatment with CLEO (a, c) or LIM (b, d) at doses of 1,3 , and $10 \mu \mathrm{g} / \mathrm{mL}$. Values are mean \pm S.E.M. $(n=5)$ and are representative of three independent experiments. ${ }^{*} P<0.05$ versus medium (RPMI 1640). ${ }^{\#} P<0.05$ versus group of neutrophils stimulated with $\mathrm{fMLP}$ or $\mathrm{LTB}_{4}$. (One-way ANOVA, Tukey's test).

TNF- $\alpha$, IL-1, IL-6, IL-10, and others [40, 41]. Various constituents of essential oils effectively inhibit cytokine production. For example, 1,8-cineol inhibited TNF- $\alpha$ and IL- $1 \beta$ in human lymphocytes. $\alpha$-Humulene reduced TNF- $\alpha$ production. Terpinen-4-ol suppressed the production of TNF- $\alpha$, IL$1 \beta$, IL- 8 , IL-10, and PGE 2 by LPS-activated monocytes $[11,42-$ $44]$. In the present study, TNF- $\alpha$ and IL-10 levels in peritoneal exudate were determined. LIM ( $500 \mathrm{mg} / \mathrm{kg}$, p.o.) significantly inhibited TNF- $\alpha$ levels but not IL-10 levels (Figures 5(a) and 5(b)). Our results indicate that the inhibitory effect of LIM on in vitro neutrophil migration may be related to the levels of TNF- $\alpha$, a proinflammatory cytokine. Other studies showed that a Citrus essential oil/magnesium salt mixture reduced TNF- $\alpha$ levels at the inflammation site. In addition, the levels of the anti-inflammatory cytokine, IL-10, in the citrus oil treatment groups were high compared to those of groups receiving the other treatments. Citrus essential oil itself did not reduce IL-10 levels [45]. LIM exerts anti-inflammatory activity by reducing $\mathrm{PGE}_{2}$ production in macrophages [19] and IL- $1 \alpha$ levels in normal human undifferentiated NCTC 2544 keratinocytes [40]. Other compounds present in CLEO also have some anti-inflammatory effects. For example, linalool inhibits in vitro NO formation [12]; $\beta$-caryophyllene reduces the expression of TNF- $\alpha$, IL- $1 \beta$, interferon- $\gamma$, and keratinocyte-derived chemokine [10]; $\alpha$-terpineol inhibits the gene expression of the IL- 6 receptor [46].

\section{Conclusions}

In conclusion, the present study found that LIM isolated from CLEO had antimigratory activity, likely by inhibiting proinflammatory mediators present in the inflammatory exudate and leukocyte chemotaxis, with the involvement of 


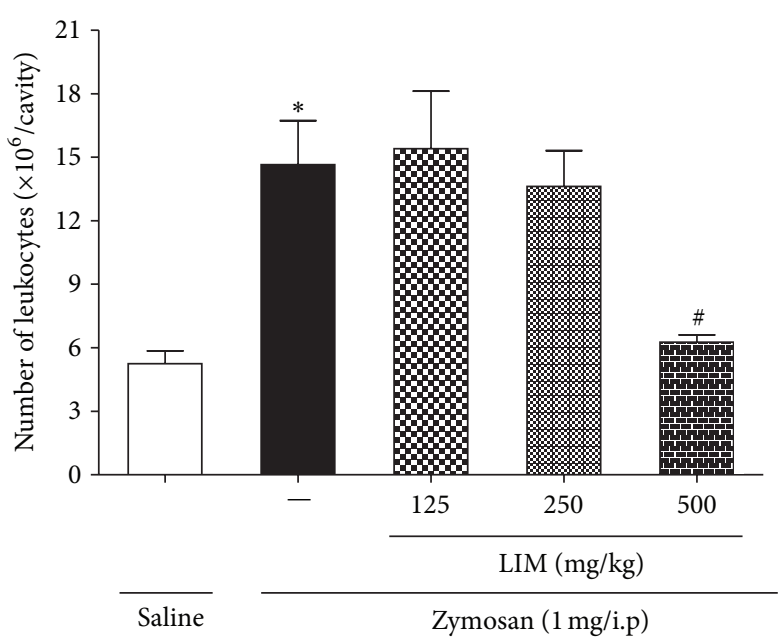

(a)

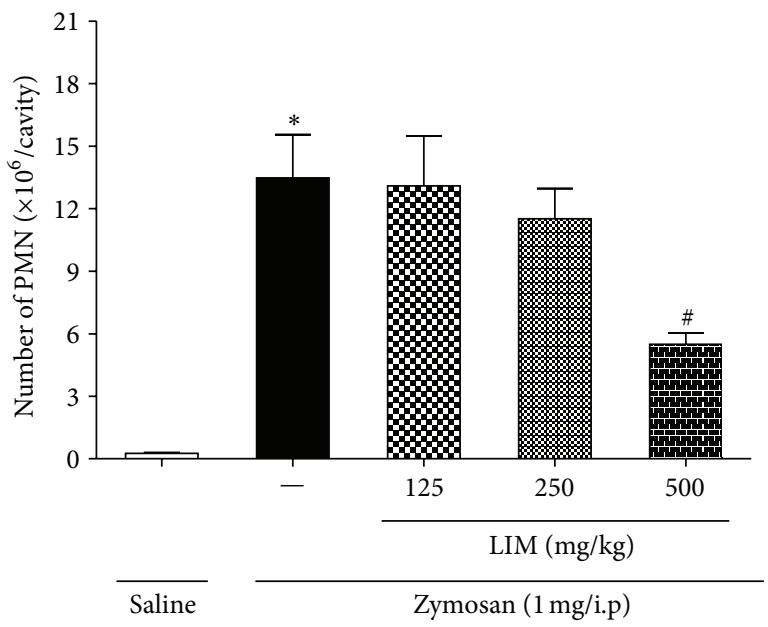

(b)

FIGURE 4: Effect of LIM treatments on leukocyte number. Effect of LIM treatments on leukocyte number 6 hours after zymosan injection ( $1 \mathrm{mg} /$ cavity/i.p) in Balb/C mice (a) and on PMN number (b). ${ }^{*} P<0.05$ versus saline (vehicle). ${ }^{\#} P<0.05$ compared versus control group. (One-way ANOVA, Tukey's test.)

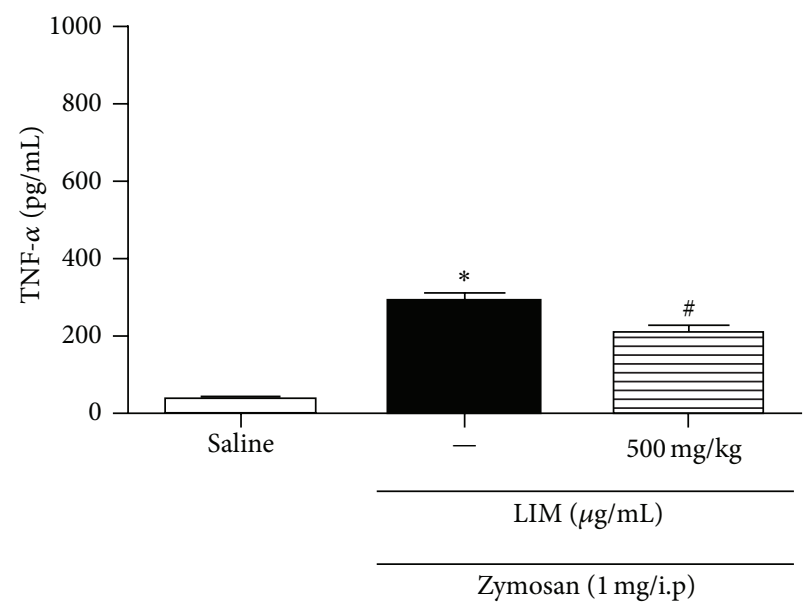

(a)

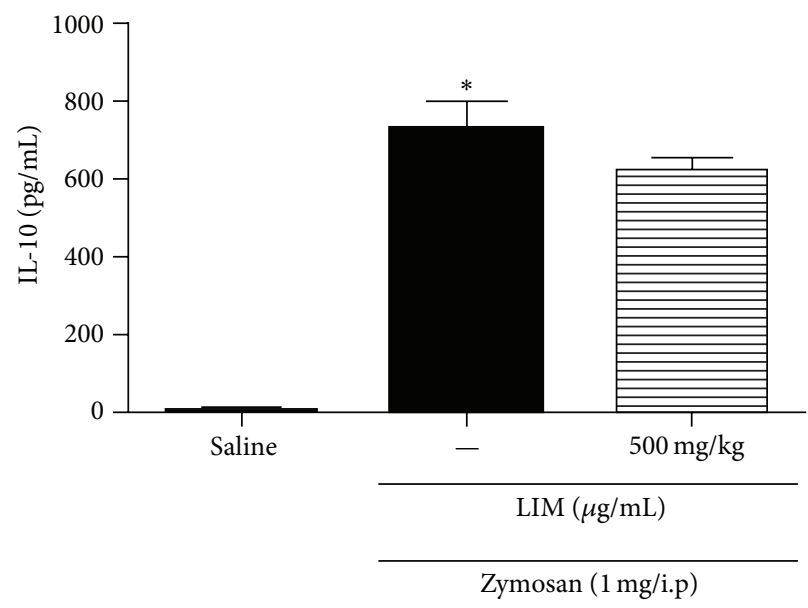

(b)

FIGURE 5: Effect of LIM on levels of TNF- $\alpha$ and IL-10. (a) Effect of LIM on levels of TNF- $\alpha$ determined in peritoneal exudate, 6 hours after zymosan injection ( $1 \mathrm{mg} /$ cavity) in Balb/C mice; (b) effect of LIM on levels of IL-10. ${ }^{*} \mathrm{P}<0.05$ versus saline (vehicle). ${ }^{\#} \mathrm{P}<0.05$ compared versus control group. (Student's $t$ test.)

inflammatory cytokines, such as TNF- $\alpha$. Further studies are needed to elucidate the anti-inflammatory mechanism of these drugs.

\section{Conflict of Interests}

The authors declare that they have no conflict of interests.

\section{Acknowledgments}

This study was supported by grants from CAPES (Coordenadoria de Aperfeiçoamento de Pessoal de Nível Superior), CNPq (Conselho Nacional de Desenvolvimento Científico e Tecnológico), and Fundação Araucária, Brazil. The authors thank Mr. Jailson Araujo Dantas and Mrs. Celia Regina Miranda for technical assistance.

\section{References}

[1] B. A. Arias and L. Ramón-Laca, "Pharmacological properties of citrus and their ancient and medieval uses in the Mediterranean region," Journal of Ethnopharmacology, vol. 97, no. 1, pp. 89-95, 2005.

[2] A. A. García, Fitoterapia: Vademecum de Prescripcion, Masson, Barcelona, Spain, 1998.

[3] J. S. Baik, S. S. Kim, J. A. Lee et al., "Chemical composition and biological activities of essential oils extracted from Korea endemic citrus species," Journal of Microbiology and Biotechnology, vol. 18, no. 1, pp. 74-79, 2008. 
[4] M. P. Leite, J. Fassin, E. M. F. Baziloni, R. N. Almeida, R. Mattei, and J. R. Leite, "Behavioral effects of essential oil of Citrus aurantium L. inhalation in rats," Brazilian Journal of Pharmacognosy, vol. 18, pp. 661-666, 2008.

[5] A. Astani, J. Reichling, and P. Schnitzler, "Comparative study on the antiviral activity of selected monoterpenes derived from essential oils," Phytotherapy Research, vol. 24, no. 5, pp. 673-679, 2010.

[6] H. S. Choi, "Lipolytic effects of citrus peel oils and their components," Journal of Agricultural and Food Chemistry, vol. 54, no. 9, pp. 3254-3258, 2006.

[7] M. L. Lota, D. De Rocca Serra, F. Tomi, C. Jacquemond, and J. Casanova, "Volatile components of peel and leaf oils of lemon and lime species," Journal of Agricultural and Food Chemistry, vol. 50, no. 4, pp. 796-805, 2002.

[8] I. Bonaccorsi, D. Sciarrone, L. Schipilliti, P. Dugo, L. Mondello, and G. Dugo, "Multidimensional enantio gas chromtography/mass spectrometry and gás chromatography-combustionisotopic ratio mass spectrometry for the authenticity assessment of lime essential oils (C. aurantifolia Swingle and C. latifolia Tanaka)," Journal of Chromatography A, vol. 1226, pp. 87-95, 2012.

[9] F. M. C. Gamarra, L. S. Sakanaka, E. B. Tambourgi, and F. A. Cabrai, "Influence on the quality of essential lemon (Citrus aurantifolid) oil by distillation process," Brazilian Journal of Chemical Engineering, vol. 23, no. 1, pp. 147-151, 2006.

[10] A. F. Bento, R. Marcon, R. C. Dutra et al., " $\beta$-caryophyllene inhibits dextran sulfate sodium-induced colitis in mice through CB2 receptor activation and PPAR $\gamma$ pathway," American Journal of Pathology, vol. 178, no. 3, pp. 1153-1166, 2011.

[11] R. Hirota, N. N. Roger, H. Nakamura, H. S. Song, M. Sawamura, and N. Suganuma, "Anti-inflammatory effects of limonene from yuzu (citrus junos tanaka) essential oil on eosinophils," Journal of Food Science, vol. 75, no. 3, pp. H87-H92, 2010.

[12] A. T. Peana, P. Rubattu, G. G. Piga et al., "Involvement of adenosine $\mathrm{A} 1$ and $\mathrm{A} 2 \mathrm{~A}$ receptors in (-)-linalool-induced antinociception," Life Sciences, vol. 78, no. 21, pp. 2471-2474, 2006.

[13] A. L. Rozza, T. D. M. Moraes, H. Kushima et al., "Gastroprotective mechanisms of Citrus lemon (Rutaceae) essential oil and its majority compounds limonene and $\beta$-pinene: involvement of heat-shock protein-70, vasoactive intestinal peptide, glutathione, sulfhydryl compounds, nitric oxide and prostaglandin $\mathrm{E}_{2}$," Chemico-Biological Interactions, vol. 189, no. 1-2, pp. 82-89, 2011.

[14] D. Roberto, P. Micucci, T. Sebastian, F. Graciela, and C. Anesini, "Antioxidant activity of limonene on normal murine lymphocytes: relation to $\mathrm{H} 2 \mathrm{O} 2$ modulation and cell proliferation," Basic and Clinical Pharmacology and Toxicology, vol. 106, no. 1, pp. 38-44, 2010.

[15] D. C. Arruda, D. C. Miguel, J. K. U. Yokoyama-Yasunaka, A. M. Katzin, and S. R. B. Uliana, "Inhibitory activity of limonene against Leishmania parasites in vitro and in vivo," Biomedicine and Pharmacotherapy, vol. 63, no. 9, pp. 643-649, 2009.

[16] S. Del Toro-Arreola, E. Flores-Torales, C. Torres-Lozano et al., "Effect of D-limonene on immune response in BALB/c mice with lymphoma," International Immunopharmacology, vol. 5, no. 5, pp. 829-838, 2005.

[17] T. M. Moraes, H. Kushima, F. C. Moleiro et al., "Effects of limonene and essential oil from Citrus aurantium on gastric mucosa: role of prostaglandins and gastric mucus secretion,"
Chemico-Biological Interactions, vol. 180, no. 3, pp. 499-505, 2009.

[18] T. Parija and B. R. Das, "Involvement of YY1 and its correlation with c-myc in NDEA induced hepatocarcinogenesis, its prevention by d-limonene," Molecular Biology Reports, vol. 30, no. 1, pp. 41-46, 2003.

[19] W. J. Yoon, N. H. Lee, and C. G. Hyun, "Limonene suppresses lipopolysaccharide-induced production of nitric oxide, prostaglandin $\mathrm{E}_{2}$, and pro-inflammatory cytokines in RAW 264.7 macrophages," Journal of Oleo Science, vol. 59, no. 8, pp. 415-421, 2010.

[20] F. C. Kummer, R. Fachini-Queiroz, C. F. Estevão-Silva et al., "Effects of thymol and carvacrol, constituents of Thymus vulgaris L. essential oil, on the inflammatory response," EvidenceBased Complementary and Alternative Medicine, vol. 2012, Article ID 657026, 10 pages, 2012.

[21] R. P. Adams, Identification of Essential Oils Components by Gas Chromatography/Quadrupole Mass Spectrometry, Allured Publishing, Carol Stream, Ill, USA, 2001.

[22] H. Zeytinoglu, Z. Incesu, B. Ayaz Tuylu, A. O. Turk, and B. Barutca, "Determination of genotoxic, antigenotoxic and cytotoxic potential of the extract from lichen Cetraria aculeata (Schreb.) Fr. in vitro," Phytotherapy Research, vol. 22, no. 1, pp. 118-123, 2008.

[23] L. J. Crossley, "Neutrophil activation by fMLP regulates FOXO (forkhead) transcription factors by multiple pathways, one of which includes the binding of FOXO to the survival factor Mcl1," Journal of Leukocyte Biology, vol. 74, no. 4, pp. 583-592, 2003.

[24] B. Heit, S. Tavener, E. Raharjo, and P. Kubes, "An intracellular signaling hierarchy determines direction of migration in opposing chemotactic gradients," Journal of Cell Biology, vol. 159, no. 1, pp. 91-102, 2002.

[25] A. Mócsai, Z. Jakus, T. Vántus, G. Berton, C. A. Lowell, and E. Ligeti, "Kinase pathways in chemoattractant-induced degranulation of neutrophils: the role of $\mathrm{p} 38$ mitogen-activated protein kinase activated by Src family kinases," Journal of Immunology, vol. 164, no. 8, pp. 4321-4331, 2000.

[26] Y. Kihara, T. Yokomizo, A. Kunita et al., "The leukotriene B4 receptor, BLT1, is required for the induction of experimental autoimmune encephalomyelitis," Biochemical and Biophysical Research Communications, vol. 394, no. 3, pp. 673-678, 2010.

[27] T. Yokomizo, T. Izumi, K. Chang, Y. Takuwa, and T. Shimizu, "A G-protein-coupled receptor for leukotriene B4 that mediates chemotaxis," Nature, vol. 387, no. 6633, pp. 620-624, 1997.

[28] D. Hamdan, M. Z. El-Readi, E. Nibret et al., "Chemical composition of the essential oils of two Citrus species and their biological activities," Pharmazie, vol. 65, no. 2, pp. 141-147, 2010.

[29] S. Kulkarni, C. Sitaru, Z. Jakus et al., "PI3Kb plays a critical role in neutrophil activation by immune complexes," Immunology, vol. 4, no. 168, 2011.

[30] C. H. Y. Wong, B. Heit, and P. Kubes, "Molecular regulators of leucocyte chemotaxis during inflammation," Cardiovascular Research, vol. 86, no. 2, pp. 183-191, 2010.

[31] G. B. Menezes, R. M. Rezende, P. E. M. Pereira-Silva, A. Klein, D. C. Cara, and J. N. Francischi, "Differential involvement of cyclooxygenase isoforms in neutrophil migration in vivo and in vitro," European Journal of Pharmacology, vol. 598, no. 1-3, pp. 118-122, 2008.

[32] E. Kolaczkowska, R. Seljelid, and B. Plytycz, "Role of mast cells in zymosan-induced peritoneal inflammation in Balb/c and mast cell-deficient WBB6F1 mice," Journal of Leukocyte Biology, vol. 69 , no. 1, pp. 33-42, 2001. 
[33] S. Cuzzocrea, B. Zingarelli, L. Sautebin et al., "Multiple organ failure following zymosan-induced peritonitis is mediated by nitric oxide," Shock, vol. 8, no. 4, pp. 268-275, 1997.

[34] S. Abe, N. Maruyama, K. Hayama, S. Inouye, H. Oshima, and H. Yamaguchi, "Suppression of neutrophil recruitment in mice by geranium essential oil," Mediators of Inflammation, vol. 13, no. 1, pp. 21-24, 2004.

[35] R. Medeiros, G. F. Passos, C. E. Vitor et al., "Effect of two active compounds obtained from the essential oil of Cordia verbenacea on the acute inflammatory responses elicited by LPS in the rat paw," British Journal of Pharmacology, vol. 151, no. 5, pp. 618-627, 2007.

[36] G. A. Nogueira de Melo, R. Grespan, J. P. Fonseca et al., "Inhibitory effects of ginger (Zingiber officinale Roscoe) essential oil on leukocyte migration in vivo and in vitro," Journal of Natural Medicines, vol. 65, pp. 241-246, 2010.

[37] G. A. Nogueira de Melo, R. Grespan, J. P. Fonseca et al., "Rosmarinus officinalis L. essential oil inhibits in vivo and in vitro leukocyte migration," Journal of Medicinal Food, vol. 14, pp. 944-946, 2011.

[38] H. L. Wright, R. J. Moots, R. C. Bucknall, and S. W. Edwards, "Neutrophil function in inflammation and inflammatory diseases," Rheumatology, vol. 49, no. 9, pp. 1618-1631, 2010.

[39] I. Utsunomiya, M. Ito, and S. Oh-ishi, "Generation of inflammatory cytokines in zymosan-induced pleurisy in rats: TNF induces IL-6 and cytokine-induced neutrophil chemoattractant (CINC) in vivo," Cytokine, vol. 10, no. 12, pp. 956-963, 1998.

[40] A. Parodi, R. Sanguineti, M. Catalano et al., "A comparative study of leukaemia inhibitory factor and interleukin- $1 \alpha$ intracellular content in a human keratinocyte cell line after exposure to cosmetic fragrances and sodium dodecyl sulphate," Toxicology Letters, vol. 192, no. 2, pp. 101-107, 2010.

[41] C. Moermans, V. Heinen, M. Nguyen et al., "Local and systemic cellular inflammation and cytokine release in chronic obstructive pulmonary disease," Cytokine, vol. 56, no. 2, pp. 298-304, 2011.

[42] P. H. Hart, C. Brand, C. F. Carson, T. V. Riley, R. H. Prager, and J. J. Finlay-Jones, "Terpinen-4-ol, the main component of the essential oil of Melaleuca alternifolia (tea tree oil), suppresses inflammatory mediator production by activated human monocytes," Inflammation Research, vol. 49, no. 11, pp. 619-626, 2000.

[43] U. R. Juergens, T. Engelen, K. Racké, M. Stöber, A. Gillissen, and H. Vetter, "Inhibitory activity of 1,8-cineol (eucalyptol) on cytokine production in cultured human lymphocytes and monocytes," Pulmonary Pharmacology and Therapeutics, vol. 17, no. 5, pp. 281-287, 2004.

[44] G. F. Passos, E. S. Fernandes, F. M. da Cunha et al., "Antiinflammatory and anti-allergic properties of the essential oil and active compounds from Cordia verbenacea," Journal of Ethnopharmacology, vol. 110, no. 2, pp. 323-333, 2007.

[45] B. Mizrahi, L. Shapira, A. J. Domb, and Y. Houri-Haddad, "Citrus oil and $\mathrm{MgCl}_{2}$ as antibacterial and anti-inflammatory agents," Journal of Periodontology, vol. 77, no. 6, pp. 963-968, 2006.

[46] S. Held, P. Schieberle, and V. Somoza, "Characterization of $\alpha$ terpineol as an anti-inflammatory component of orange juice by in vitro studies using oral buccal cells," Journal of Agricultural and Food Chemistry, vol. 55, no. 20, pp. 8040-8046, 2007. 


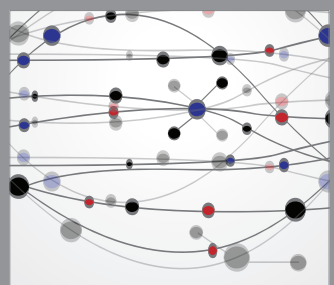

The Scientific World Journal
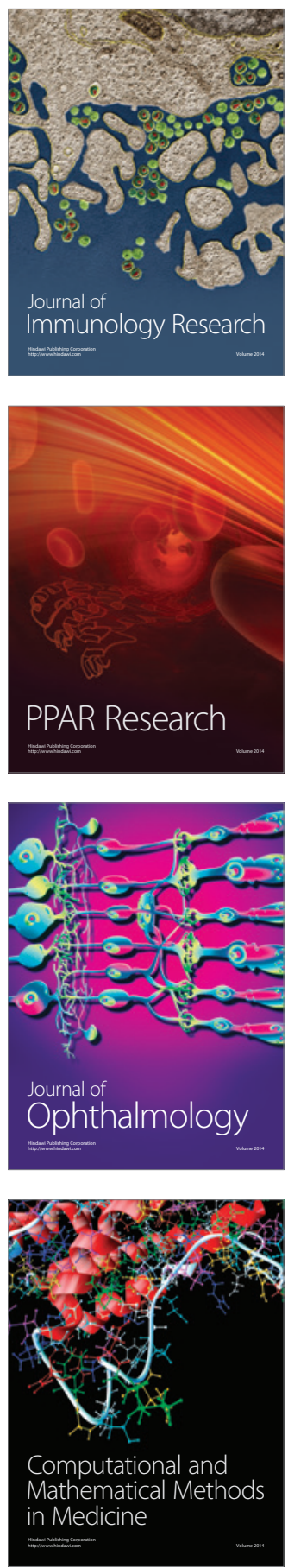

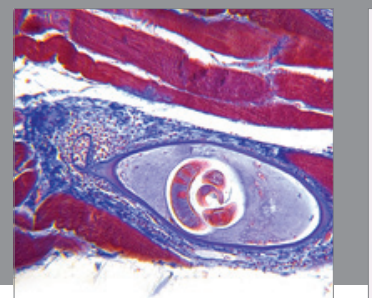

Gastroenterology

Research and Practice
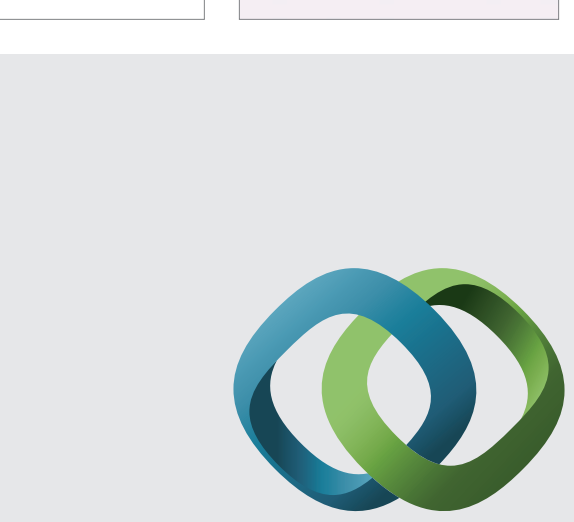

\section{Hindawi}

Submit your manuscripts at

http://www.hindawi.com
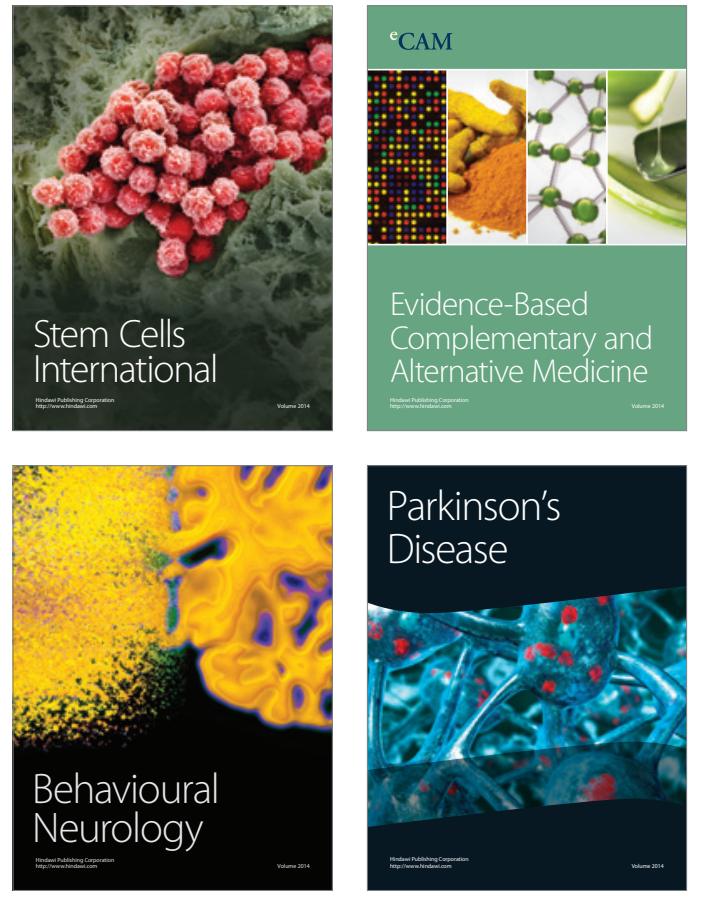
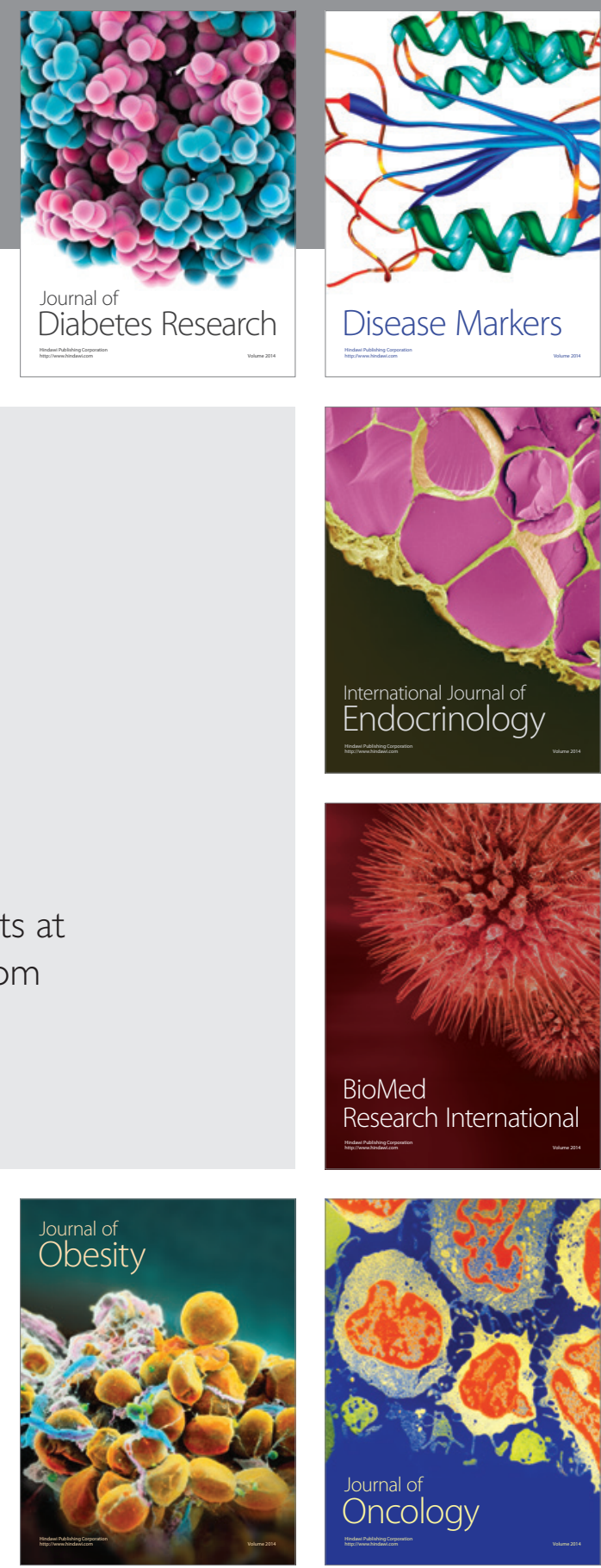

Disease Markers
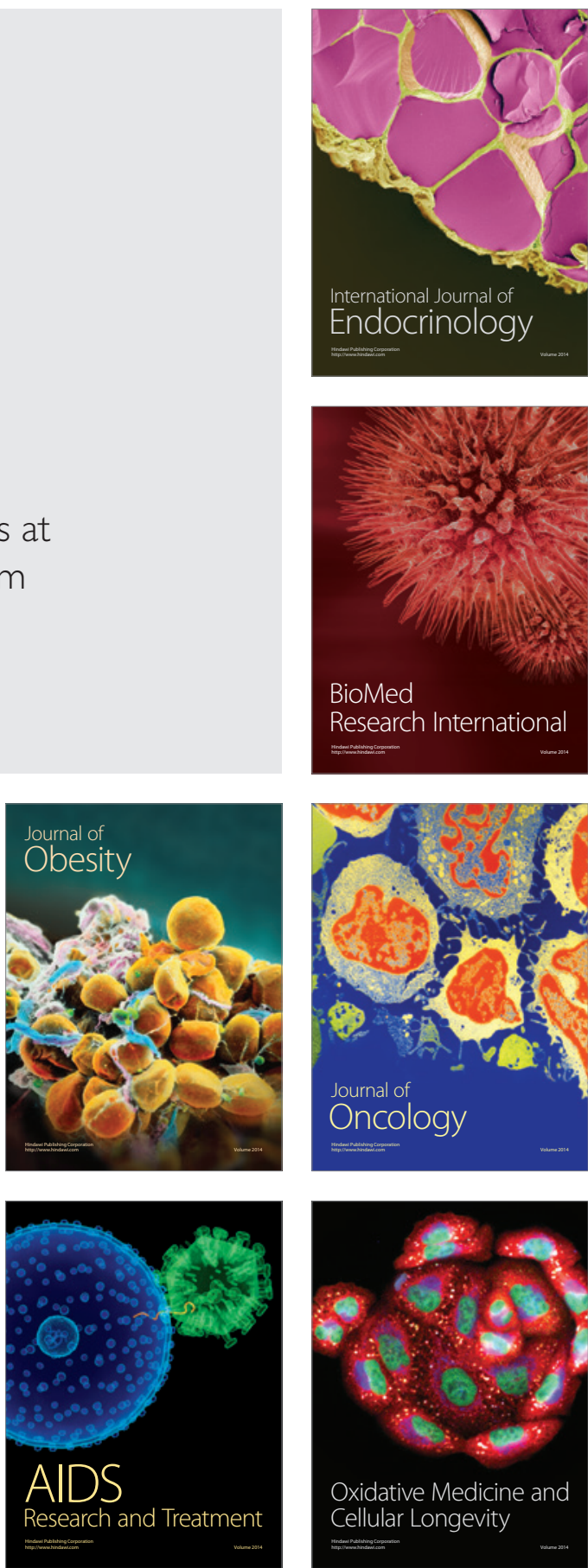